\title{
The Effects of Chronic Fetal Hyperglycemia on Substrate Uptake by the Ovine Fetus and Conceptus
}

\author{
ANTHONY F. PHILIPPS, TED S. ROSENKRANTZ, PATRICIA J. PORTE, AND JOHN R. RAYE \\ Departments of Pediatrics and Obstetrics and Gynecology, The University of Connecticut Health Center,
} Farmington, Connecticut 06002

\begin{abstract}
Hyperglycemia in fetal sheep has been shown to increase the fetal metabolic rate. Fetal venous glucose infusion was performed in eight late gestation, chronically catheterized fetal lambs to assess any changes in substrate uptake by the ovine uterus and conceptus. Fetal glucose infusion $\left(11.9 \pm 0.6 \mathrm{mg}\right.$ glucose $\left.\cdot \mathrm{kg}^{-1} \cdot \mathrm{min}^{-1}\right)$ caused a stable increase in fetal plasma glucose concentration approximately 3 -fold above baseline. The fetal glucose entry rate increased from $6.6 \pm 0.7$ to $9.3 \pm 0.6 \mathrm{mg} \cdot \mathrm{kg}^{-1}$. $\min ^{-1}$ by day 3 of infusion $(p<0.01)$ despite a net umbilical glucose excretion during the period of fetal hyperglycemia. Due to a concomitant increase in fetal oxygen consumption, no change in fetal glucose $/ \mathrm{O}_{2}$ quotient was observed. A significant relationship was noted $(p<0.02)$ between the fetal glucose entry rate and the rate of fetal oxygen consumption. Fetal glucose infusion caused a decrease in uterine glucose uptake as well. No changes were observed in calculated net placental glucose uptake although the relative fetal contribution increased from net placental exit to fetus to a placental uptake amounting to $20.8 \pm 5.8 \%$ of the total placental glucose uptake $(p<0.01)$. Although no changes in fetal lactate concentration occurred, both maternal and fetal lactate entry rates increased, the magnitude of increase being significantly related to fetal glucose concentration. Both maternal and fetal insulin concentrations rose during the period of fetal hyperglycemia and were related to the respective increases of maternal or fetal substrate uptakes but not to fetal oxygen consumption. These studies suggest that glucose induces significant stimulation of fetal oxidative metabolism and that fuel needs during this period are met by accelerated fetal glucose entry as well as accelerated placental production of lactate. Superimposed hypoxemia during these circumstances might be expected to have a greater effect on fetal oxygenation and $\mathrm{pH}$ than during normoxemic circumstances. (Pediatr Res 19: 659-666, 1985)
\end{abstract}

\section{Abbreviations}

f, umbilical blood flow $\left(\mathrm{ml} \cdot \mathrm{kg}^{-1} \cdot \mathrm{min}^{-1}\right)$

$\mathrm{F}$, uterine blood flow $\left(\mathrm{ml} \cdot \mathrm{min}^{-1}\right)$

glu, glucose concentration $(\mathrm{mg} / \mathrm{dl})$

lac, lactate concentration ( $\mathrm{mM}$ )

ala, alanine concentration ( $\mathrm{mM})$

Received November 9, 1984; accepted February 27, 1985.

Address reprint requests and correspondence to Anthony F. Philipps, M.D., Department of Pediatrics, Division of Neonatology, University of Connecticut Health Center, Farmington, CT 06032.

Supported by grants from the University of Connecticut Research Foundation and the National Institutes of Health (AM 26067)

\author{
A, maternal distal aorta \\ $\mathrm{V}$, uterine vein \\ a, fetal distal aorta \\ $\mathbf{v}$, umbilical vein \\ $Q$, entry rate or excretion rate \\ $\mathrm{C}_{\mathrm{V}-\mathrm{A}}$, uterine venoarterial concentration difference \\ $\mathrm{Cv}$-a, umbilical venoarterial concentration difference \\ $\mathbf{Q}_{02}$, oxygen consumption
}

Common abnormalities in human infants of diabetic mothers include gross fetal macrosomia and visceromegaly with attendant postnatal hyperinsulinemia and hypoglycemia $(1,2)$. Autopsied infants of diabetic mothers have shown evidence of significant pancreatic islet hyperplasia $(3,4)$ to support the hypothesis that excesses in maternal-fetal glucose transfer are responsible for fetal pancreatic islet stimulation and subsequent signs of fetal insulin excess. However, some features shared by fetuses of severely diabetic mothers such as an increased late stillborn rate and a poor ability to tolerate labor have not been adequately explained by the mechanism of excessive substrate transfer. Previous information obtained from chronically catheterized fetal sheep has suggested that fetal glucose infusion is associated with stimulation of fetal oxygen consumption (5) and subsequent arterial hypoxemia. Severe fetal hyperglycemia in this model causes metabolic acidosis and fetal demise (6). Since less severe hyperglycemia appears to stimulate fetal oxidative metabolism, the goals of the current study were to characterize the alterations in substrate uptake and production by the pregnant ovine uterus and contents before and during chronic defined fetal glucose infusions.

\section{METHODS}

Surgical preparation. Eight pregnant ewes were studied between 120-140 days of gestation. Term gestation in the sheep is approximately 150 days. Three ewes had twin gestations and the remainder singletons. In twin preparations, only one twin was catheterized. After preoperative sedation (intravenous pentobarbital) and anesthesia (intrathecal pontocaine), polyvinyl chloride catheters were implanted via a hysterotomy incision. Catheters were placed in the maternal distal aorta and uterine vein of the pregnant uterine horn and in the fetal distal aorta, common umbilical vein, and inferior vena cava. An amniotic space catheter was inserted for instillation of antibiotics postoperatively. All catheters were then tunnelled sucutaneously to a pouch on the ewe's flank for further sampling. All ewes were treated postoperatively as previously described (7) during a 4- to 5-day recovery period. 
Table 1. Formulas

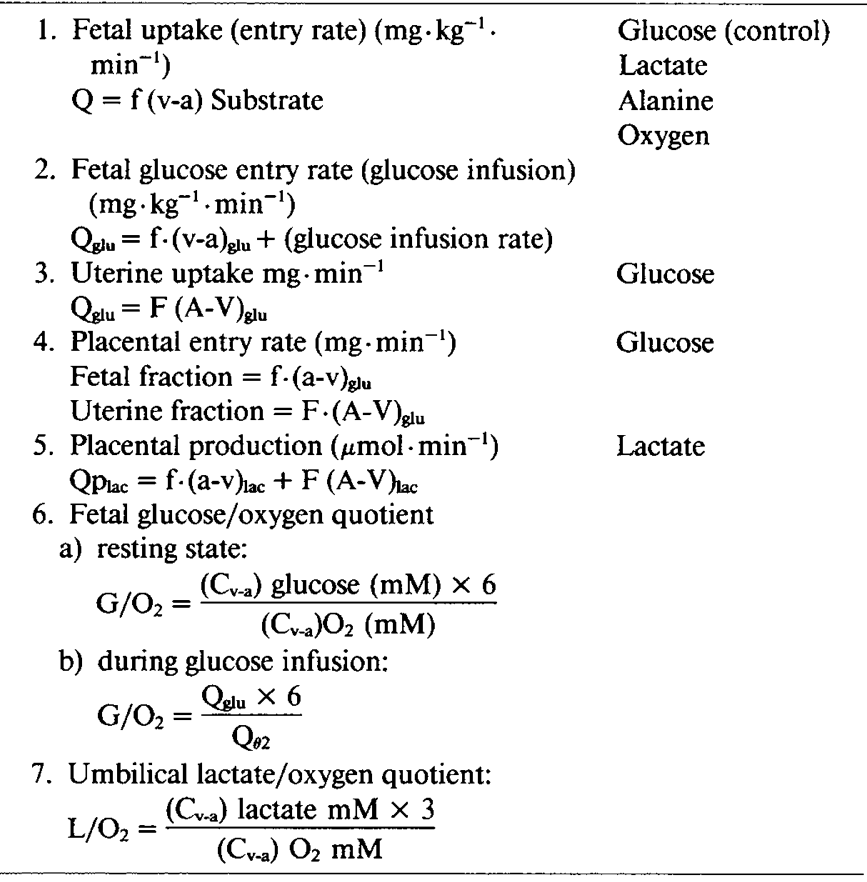

Experimental protocol. During a 2-day control period samples were drawn simultaneously from maternal aortic, uterine venous, fetal distal aortic, and umbilical venous catheters twice daily. Whole blood concentrations of glucose, lactate, alanine, and oxygen were obtained. In addition, plasma concentrations of glucose and insulin were obtained from the maternal and fetal arterial catheters. Uterine and umbilical blood flows were estimated using the antipyrine steady state diffusion method (8). The Fick principle was then applied in calculation of basal uptakes of glucose, lactate, alanine, and oxygen across the uterine and umbilical circulations (Table 1). Uteroplacental glucose and oxygen uptakes during the control period were calculated as the difference between the glucose or oxygen uptakes from the uterine and umbilical circulations, respectively (9).

At the conclusion of the 2-day control period, fetal glucose infusion was begun using the fetal vena caval catheter calculated to deliver $12.5 \mathrm{mg}$ glucose $\cdot \mathrm{kg}^{-1} \cdot \mathrm{min}^{-1}$ to each fetus by means of precalibrated syringe pumps (Orion Research Products, Cambridge, MA; Harvard Apparatus, Millis, MA). Infusions of $50 \%$ glucose in sterile water resulted in delivery volumes of between 3 and $6 \mathrm{ml} / \mathrm{h}$ and lasted for $72 \mathrm{~h}$. Beginning $24 \mathrm{~h}$ after the commencement of glucose infusion, venoarterial sampling across both uterine and umbilical circulations was performed twice daily for reassessment of the uptakes or entry rates of glucose and oxygen during hyperglycemia ${ }^{1}$ as well as any alterations in circulating insulin concentrations. Uptakes of lactate and alanine were measured at 24 and $72 \mathrm{~h}$ of infusion to decrease the total blood volume withdrawn.

Although oxygen consumption and the entry (or exit) rates of lactate and alanine in the experimental period could be calculated as during control, calculation of the fetal $\mathrm{Q}_{\mathrm{glu}}$ (Table 1) required calculation of the sum of the glucose infusion rate, the product of $f$ and the $\mathrm{C}_{\mathrm{v} \text {-aglu }}$ and an additional factor to account for the rate of glucose accumulation in amniotic fluid. However, serial sampling of amniotic fluid during glucose infusion detected only small changes (increments of $<5 \mathrm{mg} \cdot \mathrm{dl}^{-1} \cdot \mathrm{day}^{-1}$ ). Assuming an average amniotic and allantoic fluid volume for the sheep of 1 liter, (10) the value for this factor would be $0.1 \%$ of the glucose

\footnotetext{
${ }^{1}$ The term entry rate will be substituted for uptake or consumption when applied to the substrates glucose, lactate, or alanine since the ultimate fate of these substrates was not determined in the present study.
}

infusion rate. This factor was considered negligible and was not considered further in the calculation of glucose entry rate.

Similarly, during the period of hyperglycemia, a portion of the placental glucose entry was derived from the umbilical circulation (i.e. net glucose exit from the umbilical circulation). Therefore, the placental glucose entry rate equaled the sum of the contributions from both uterine and umbilical circulations, calculated as the product of their respective flows and arteriovenous glucose concentration differences (equation 4, Table 1).

In addition, since in most cases significant placental lactate production was apparent with net lactate entry from placenta into uterine and umbilical circulations, the conventional venoarterial differences (equation 5) have been utilized to describe net placental lactate exit rates.

Glucose and lactate/oxygen quotients were calculated using formulas 6 and 7 (Table 1).

Because of the difficulty in estimating the fetal growth rate per day during fetal hyperglycemia, data related to umbilical substrate uptake and oxygen consumption were calculated arbitrarily on a per kilogram basis using the initial (control) estimated fetal weight. Fetal weight at the onset of the control period was estimated from the breeder's dates and fetal lamb growth curves for singleton and twin lambs accumulated in our laboratory. At the conclusion of the study protocol in each preparation, fetal weight was obtained at sacrifice or delivery. Calculations of substrate uptake or delivery were based on control fetal weight extrapolated from known delivery weight. Although fetal lamb weight increases by $2-4 \%$ /day in late gestation (11), no comparable increase in umbilical glucose uptake occurs with growth after 120 days gestation (12). Thus, any observed increase in umbilical glucose uptake during the 5-day periods of expeirmentation would not be expected solely on the basis of advancing gestational age. To corroborate this observation, four fetuses of similar gestational age were used as noninfused controls. Samples were obtained 5 days apart from the appropriate fetal vascular catheters and analyzed for blood flow, $\mathrm{O}_{2}$ content, glucose concentration, and calculations of fetal oxygen consumption and umbilical glucose uptake. Lactate uptake was not studied in these fetuses.

Biochemical methods. Whole blood glucose concentration was assayed in duplicate by means of the glucose oxidase technique (13) with prior deproteinization with barium hydroxide and zinc sulfate. Plasma glucose concentrations were assayed with a simplified glucose oxidase technique (Beckman Instruments, Palo Alto, CA). Whole blood lactate concentration, also measured in duplicate, was assayed using the enzymatic method of Olsen (14). Whole blood alanine concentration was also measured enzymatically (15) using alanine dehydrogenase. Blood samples for lactate and alanine were first deproteinized with $5.1 \%$ perchloric acid and then centrifuged. The supernatants were then stored at $-70^{\circ}$ $\mathrm{C}$ until time of batch assay. Whole blood oxygen content was measured using the Lex- $\mathrm{O}_{2}$-Con (Lexington Instruments, Waltham, MA), which was calibrated daily using distilled water saturated with oxygen at $0^{\circ} \mathrm{C}$. Blood for oxygen content analysis was withdrawn into capillary tubes pretreated with sodium fluoride. Plasma arterial insulin concentrations were measured in triplicate using a modified insulin radioimmunoassay (7) with a double antibody separation technique. Ovine insulin standards were used in the assay (supplied by Mary A. Root, Ph.D., Eli Lilly Research Laboratory, Indianapolis, IN). Blood for insulin assay was withdrawn into chilled test tubes containing $10 \mathrm{U}$ heparin each, centrifuged, and the supernatant stored at $-70^{\circ} \mathrm{C}$ for later analysis. Antipyrine concentration from duplicate plasma samples was determined using a Technicon Autoanalyzer (Technicon Instruments, Tarrytown, NY).

Statistical methods. All results are expressed as mean \pm SEM. Statistical significiance was assessed with aid of the paired Student's $t$ test and two-way analyses of variance. Linear regression analysis was performed using the least squares method. 


\section{RESULTS}

Nine separate glucose infusions were performed in the eight fetal lambs. Results of the second glucose infusion in one animal are included in the pooled data as they were statistically similar to results obtained in other preparations (black circles, Figs. 24). Fetal glucose infusion resulted in a sustained elevation in plasma arterial glucose concentration from the basal value of $26.0 \pm 1.9$ to $58.8 \pm 3.7 \mathrm{mg} / \mathrm{dl}(p<0.001$, Fig. 1 , Table 2$)$. Recalculation of the glucose infusion rates with fetal weights extrapolated from known delivery weights yielded a mean infusion rate of $11.9 \pm 0.6 \mathrm{mg}$ glucose $\cdot \mathrm{kg}^{-1} \cdot \mathrm{min}^{-1}$. Umbilical venoarterial glucose concentration difference, initially $+2.5 \pm 0.2$ $\mathrm{mg} / \mathrm{dl}$, fell during glucose infusion, the decrements being significant at each day of infusion $(p<0.01)$. The data showing negative umbilical venoarterial glucose differences indicated net fetal glucose exit on days 2 and 3 of infusion representing 30.5 and $16.3 \%$ of the glucose infusion rate, respectively. Umbilical blood flow during hyperglycemia was unchanged from the con-

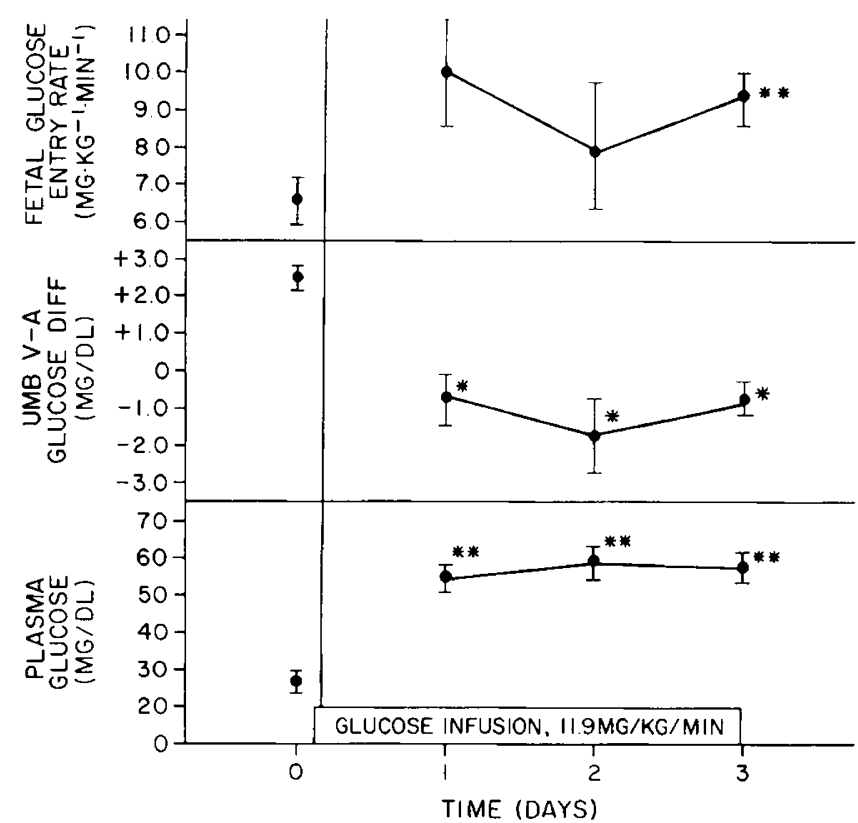

Fig. 1. Fetal plasma glucose concentrations, umbilical venoarterial glucose concentration differences, and fetal glucose entry rates before and during nine glucose infusions in eight fetal lambs. trol value of $232 \pm 7 \mathrm{ml} \cdot \mathrm{kg}^{-1} \cdot \mathrm{min}^{-1}$. The calculated net fetal glucose entry rate rose from $6.6 \pm 0.7 \mathrm{mg} \cdot \mathrm{kg}^{-1} \cdot \mathrm{min}^{-1}(19.6 \pm$ $\left.3.4 \mathrm{mg} \cdot \mathrm{min}^{-1}\right)$ to $9.3 \pm 0.6 \mathrm{mg} \cdot \mathrm{kg}^{-1} \cdot \mathrm{min}^{-1}(33.5 \pm 4.0 \mathrm{mg}$. $\left.\min ^{-1}\right)$ by day 3 of infusion $(p<0.01)$. Glucose entry rates on days 1 and 2 of infusion were elevated above baseline, but not significantly so due to interanimal variation.

As reported elsewhere (5), fetal glucose infusion resulted in a fall in distal arterial oxygen content with significant increases in the umbilical venoarterial oxygen content difference as well as fetal $\mathrm{Q}_{02}$. Fetal $\mathrm{Q}_{02}$ rose from $8.1 \pm 0.4 \mathrm{ml} \cdot \mathrm{kg}^{-1} \cdot \mathrm{min}^{-1}$ to a maximum value of $10.6 \pm 0.3 \mathrm{ml} \cdot \mathrm{kg}^{-1} \cdot \mathrm{min}^{-1}$ by day 3 of infusion (Table 2). Because of the concomitant elevations in fetal glucose entry rate and oxygen consumption, no changes were noted in $\mathrm{G} / \mathrm{O}_{2}$ from the basal value of $0.54 \pm 0.05$ during hyperglycemia. In contrast, no changes in umbilical glucose uptake or oxygen consumption were noted in the four uninfused fetal lambs $\left(\mathrm{Q}_{\mathrm{glu}}: 7.5 \pm 1.8\right.$ to $6.1 \pm 1.5 \mathrm{mg} \cdot \mathrm{kg}^{-1} \cdot \mathrm{min}^{-1}$ and $\mathrm{Q}_{02}$ :

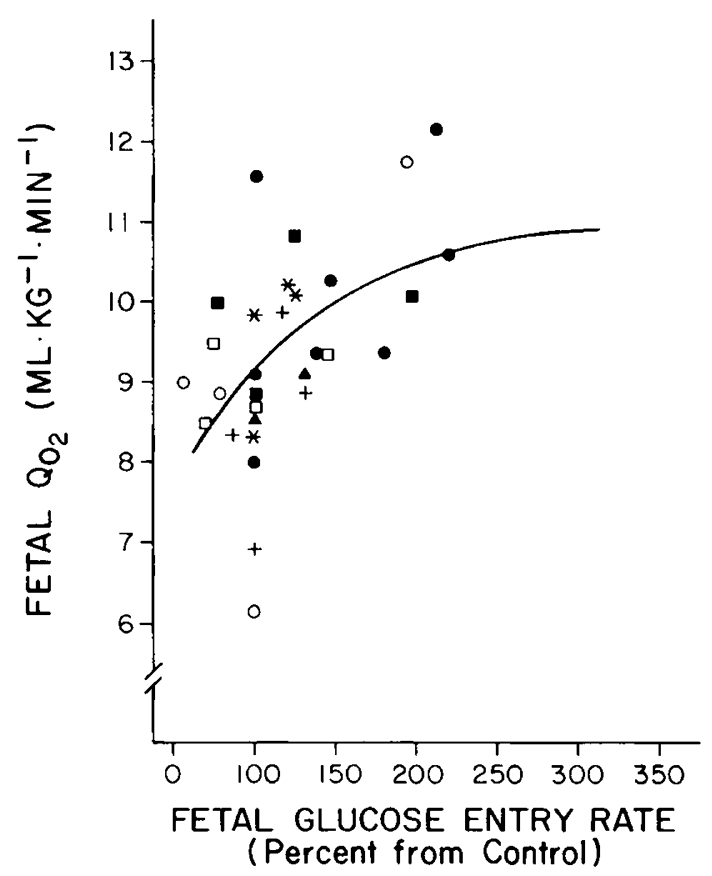

Fig. 2. Relationship between fetal glucose entry rate and fetal $Q_{02}$ during control and experimental periods. Each symbol represents a different animal preparation $(n=30, r=0.44, \mathrm{y}=3.41 \log x+2.5, p$ $<0.02$ ).

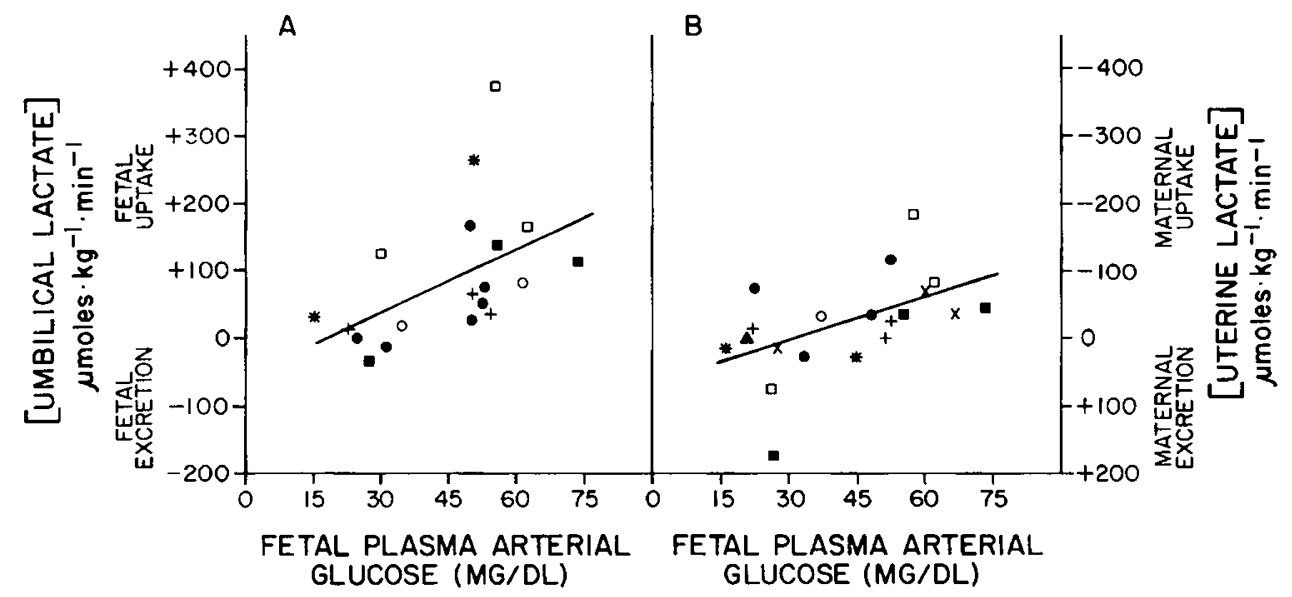

Fig. 3. $A$, relationship between fetal arterial plasma glucose concentration and umbilical lactate uptake or excretion during control and experimental periods $(n=19, r=0.46, \mathrm{y}=2.96 \times-2.43, p<0.05) . B$, relationship between fetal arterial plasma glucose concentrations and uterine lactate uptake (maternal excretion) or uterine excretion (maternal uptake) during control and experimental periods $(n=20, r=0.49, \mathrm{y}=$ $-2.11 \times+70.1, p<0.02)$. 
$8.5 \pm 0.8$ to $8.7 \pm 0.9 \mathrm{ml} \cdot \mathrm{kg}^{-1} \cdot \mathrm{min}^{-1}$, respectively) over a 5 -day period of observation. Umbilical $\mathrm{G} / \mathrm{O}_{2}$ in these uninfused fetuses fell from $0.65 \pm 0.12$ to $0.54 \pm 0.10$ but the change was not statistically significant.

A significant relationship (Fig. 2, $p<0.02$ ) was present between the fetal glucose entry rate (expressed as percentage from control) and the rate of fetal oxygen consumption. Maximal stimulation of fetal oxygen consumption was apparent at fetal glucose entry rates approximately 2 -fold above normal.

Despite the exit of glucose from the umbilical circulation during fetal hyperglycemia, no significant alterations in maternal glucose concentrations were observed (Table 3). However, the uterine venoarterial glucose concentration difference did fall (from $3.8 \pm 0.4$ to $2.0 \pm 0.5 \mathrm{mg} / \mathrm{dl}$ by $24 \mathrm{~h}$ of glucose infusion, $p<0.02$ ). Uterine blood flow remained constant (basal $\mathrm{F}=1388$ $\pm 180 \mathrm{ml} \cdot \mathrm{min}^{-1}$ ) and thus uterine glucose uptake fell significantly by $24 \mathrm{~h}$ of infusion (from $46.9 \pm 6.0$ to $29.3 \pm 8.1 \mathrm{mg}$. $\min ^{-1}, p<0.02$ ). Although values obtained at $72 \mathrm{~h}$ of infusion showed a decrement in uterine glucose uptake as well, statistical significance was not achieved.

Table 4 presents the available data regarding placental glucose entry and lactate excretion in preparations where both the uterine and umbilical circulations could be studied simultaneously. Net placental glucose entry during hyperglycemia as calculated from the formula in Table 1 showed no change from the basal value of $39.8 \pm 10.7 \mathrm{mg} \cdot \mathrm{min}^{-1}\left(221.6 \pm 59 \mu \mathrm{mol} \cdot \mathrm{min}^{-1}\right)$. However, the relative fetal contribution to placental glucose uptake was increased from over the entire infusion period. This value changed from a net placental excretion to the fetus in the control period and amounted to $22 \%$ of the total $\mathrm{Q}_{\text {plac }}$ during fetal hyperglycemia when the data were pooled $(p<0.01)$.

Fetal lactate concentrations measured during hyperglycemia were not significantly elevated above control although a trend was evident toward an increase in umbilical venous lactate concentration. However, the umbilical venoarterial lactate concentration differences did rise significantly by $24 \mathrm{~h}$ (Table 2). Calculated fetal lactate entry rates and $\mathrm{L} / \mathrm{O}_{2}$ quotients were significantly elevated during hyperglycemia, both rising 3- to 4fold above baseline. The increase in umbilical lactate entry was related linearly to the fetal plasma arterial glucose concentration as shown in Figure $3 A$. No changes in maternal blood concentrations of lactate from the pooled data were noted although a trend toward increasing net uterine lactate excretion was noted. As shown in Figure $3 B$, however, a linear relationship was apparent between increasing fetal plasma glucose concentrations and increasing uterine lactate excretion into the maternal circulation.

Placental lactate production, calculated as the sum of umbilical lactate entry and uterine lactate excretion, rose from a control

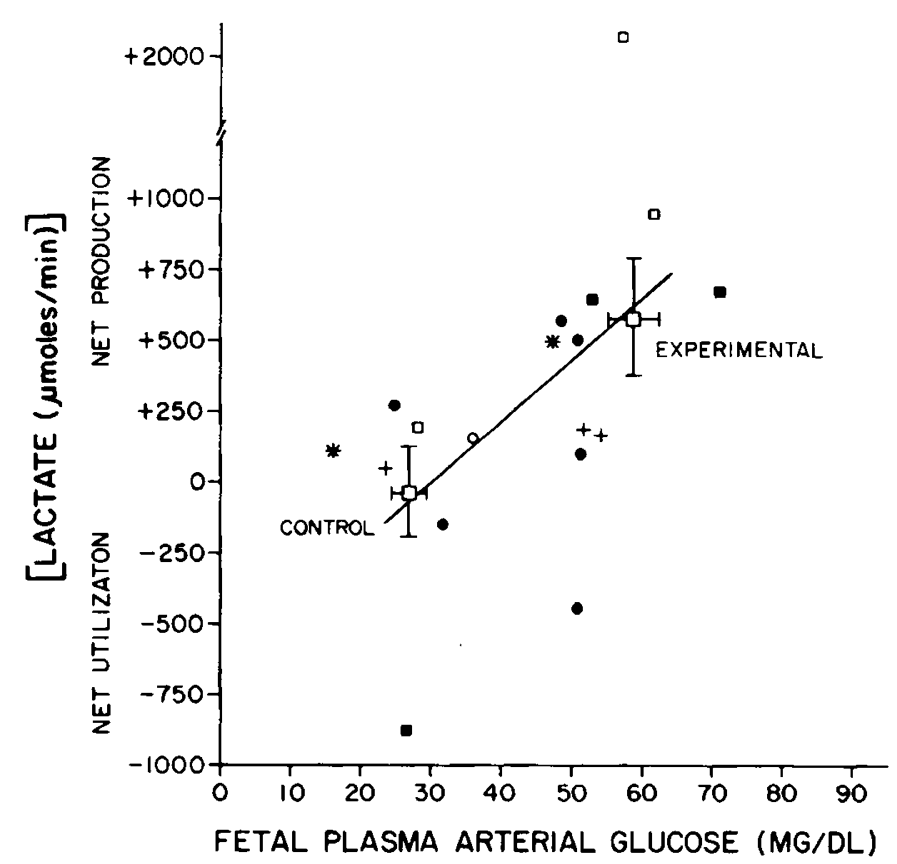

Fig. 4. Relationship between fetal arterial plasma glucose concentration and net placental lactate production or utilization during control and experimental periods. Bars represent $\pm 1 \operatorname{SEM}(n=18, r=0.55$, y $=21.4 \times-635, p<0.03$ ).

Table 2. Mean fetal concentrations of substrates, oxygen, and insulin before and during glucose infusion

\begin{tabular}{|c|c|c|c|c|}
\hline & Control & Day 1 & Day 2 & Day 3 \\
\hline \multicolumn{5}{|l|}{ Umbilical blood flow } \\
\hline$\left(\mathrm{ml} \cdot \mathrm{kg}^{-1} \cdot \mathrm{min}^{-1}\right)$ & $232 \pm 7(8)$ & $226 \pm 11(8)$ & $223 \pm 13(7)$ & $241 \pm 15(7)$ \\
\hline$\left(\mathrm{ml} \cdot \mathrm{min}^{-1}\right)$ & $841 \pm 25$ & $819 \pm 40$ & $804 \pm 47$ & $872 \pm 52$ \\
\hline \multicolumn{5}{|l|}{ Glucose } \\
\hline $\begin{array}{l}\text { Plasma arterial concentration (mg/ } \\
\text { dl) }\end{array}$ & $26.0 \pm 1.9(9)$ & $53.3 \pm 1.7^{*}(9)$ & $58.8 \pm 3.7^{*}(9)$ & $56.7 \pm 3.5^{*}(8)$ \\
\hline $\begin{array}{l}\text { Whole blood umbilical v-a differ- } \\
\text { ence ( } \mathrm{mg} / \mathrm{dl})\end{array}$ & $2.5 \pm 0.2(8)$ & $-0.9 \pm 0.7^{*}(8)$ & $-1.6 \pm 0.8^{*}(7)$ & $-0.8 \pm 0.3^{*}(7)$ \\
\hline $\begin{array}{l}\text { Fetal entry rate }(\mathrm{Qglu})\left(\mathrm{mg} \cdot \mathrm{kg}^{-1}\right. \\
\left.\min ^{-1}\right)\end{array}$ & $6.6 \pm 0.7(8)$ & $10.0 \pm 1.9(8)$ & $7.7 \pm 1.9(7)$ & $9.3 \pm 0.6^{*}(7)$ \\
\hline \multicolumn{5}{|l|}{ Lactate } \\
\hline $\begin{array}{l}\text { Whole blood arterial concentration } \\
(\mathrm{mM})\end{array}$ & $2.86 \pm 0.34(7)$ & $3.43 \pm 0.56(7)$ & & $3.18 \pm 0.51(6)$ \\
\hline Whole blood v-a difference (mM) & $0.08 \pm 0.09(7)$ & $0.51 \pm 0.2 \dagger(7)$ & & $0.51 \pm 0.27(6)$ \\
\hline Fetal entry rate $\left(Q_{1}\right) \mu \mathrm{mol} \cdot \mathrm{kg}^{-1} \cdot \min$ & $20 \pm 20(7)$ & $115 \pm 30+(7)$ & & $92 \pm 50 \ddagger(6)$ \\
\hline \multicolumn{5}{|l|}{ Oxygen } \\
\hline $\begin{array}{l}\text { Fetal consumption }\left(\mathrm{Q}_{02}\right)\left(\mathrm{ml} \cdot \mathrm{kg}^{-1}\right. \\
\left.\min ^{-1}\right)\end{array}$ & $8.1 \pm 0.4(8)$ & $9.4 \pm 0.3^{*}(8)$ & $9.9 \pm 0.4^{*}(7)$ & $10.6 \pm 0.3^{*}(7)$ \\
\hline Glucose $/ \mathrm{O}_{2}$ & $0.54 \pm 0.05(8)$ & $0.67 \pm 0.10(8)$ & $0.58 \pm 0.14(7)$ & $0.70 \pm 0.06(7)$ \\
\hline Lactate $/ \mathrm{O}_{2}$ & $0.12 \pm 0.16(78)$ & $0.83 \pm 0.20^{*}(7)$ & & $0.72 \pm 0.34 *(6)$ \\
\hline \multicolumn{5}{|l|}{ Insulin } \\
\hline $\begin{array}{l}\text { Plasma arterial concentration }(\mu \mathrm{U} / \\
\mathrm{ml})\end{array}$ & $12.5 \pm 1.8(9)$ & $23.6 \pm 3.1 \dagger(9)$ & $29.9 \pm 8.3 \ddagger(9)$ & $20.4 \pm 4.7 \ddagger(8)$ \\
\hline
\end{tabular}

$* p<0.01$

$\dagger p<0.02$.

$\ddagger p<0.05$.

$n$ in parentheses. 
Table 3. Mean maternal concentrations of substrates before and during fetal glucose infusion

\begin{tabular}{|c|c|c|c|}
\hline & Control & Day 1 & Day 3 \\
\hline Uterine blood flow $\left(\mathrm{ml} \cdot \mathrm{min}^{-1}\right)$ & $1388 \pm 180(8)$ & $1469 \pm 167(8)$ & $1530 \pm 247(7)$ \\
\hline Uterine oxygen consumption $\left(\mathrm{ml} \cdot \mathrm{min}^{-1}\right)$ & $50.4 \pm 4.9(8)$ & $55.4 \pm 6.7(8)$ & $57.8 \pm 7.5(7)$ \\
\hline \multicolumn{4}{|l|}{ Glucose } \\
\hline Plasma arterial concentration $(\mathrm{mg} / \mathrm{dl})$ & $74.6 \pm 3.1(9)$ & $70.0 \pm 1.8(9)$ & $75.1 \pm 3.5(9)$ \\
\hline Whole blood arterial concentration $(\mathrm{mg} / \mathrm{dl})$ & $58.7 \pm 1.8(8)$ & $58.0 \pm 7.6(8)$ & $63.4 \pm 5.4(7)$ \\
\hline Whole blood uterine venous concentration $(\mathrm{mg} / \mathrm{dl})$ & $55.1 \pm 1.8(8)$ & $56.1 \pm 2.6(8)$ & $61.6 \pm 5.7(7)$ \\
\hline Uterine a-v difference $(\mathrm{mg} / \mathrm{dl})$ & $3.8 \pm 0.4(8)$ & $2.0 \pm 0.5^{*}(8)$ & $1.8 \pm 0.7(7)$ \\
\hline Uterine entry rate $Q_{G}\left(\mathrm{mg} \cdot \min ^{-1}\right)$ & $46.9 \pm 6.0(8)$ & $29.3 \pm 8.1^{*}(8)$ & $34.0 \pm 17.0(7)$ \\
\hline \multicolumn{4}{|l|}{ Lactate } \\
\hline Whole blood arterial concentration (mM) & $1.11 \pm 0.19(8)$ & $1.02 \pm 0.16(7)$ & $1.08 \pm 0.50(6)$ \\
\hline Whole blood uterine venous concentration (mM) & $1.04 \pm 0.17(8)$ & $1.09 \pm 0.19(7)$ & $1.15 \pm 0.63(6)$ \\
\hline Uterine A-V difference (mM) & $0.07 \pm 0.07(8)$ & $-0.05 \pm 0.13(7)$ & $-0.08 \pm 0.07(6)$ \\
\hline Uterine entry rate $\mathrm{Q}_{\mathrm{L}}\left(\mu \mathrm{mol} \cdot \mathrm{min}^{-1}\right)$ & $98 \pm 112(8)$ & $-86.5 \pm 66.0(7)$ & $-106.4 \pm 176(6)$ \\
\hline \multicolumn{4}{|l|}{ Insulin } \\
\hline Plasma arterial concentration $\left(\mu \mathrm{U} \cdot \min ^{-1}\right)$ & $35.5 \pm 4.0(9)$ & $56.6 \pm 7.9^{*}(9)$ & $58.6 \pm 8.5^{*}(9)$ \\
\hline
\end{tabular}

$* p<0.02$.

$n$ in parentheses.

Table 4. Placental substrate metabolism before and during fetal hyperglycemia

\begin{tabular}{|c|c|c|c|c|}
\hline & $\begin{array}{l}\text { Control } \\
(\mathrm{n}=7)\end{array}$ & $\begin{array}{c}\text { Day 1 } \\
(\mathrm{n}=7)\end{array}$ & $\begin{array}{c}\text { Day } 3 \\
(\mathrm{n}=5) \\
\end{array}$ & $\begin{array}{c}\text { Pooled } \\
\text { experimental } \\
(n=12)\end{array}$ \\
\hline Utero placental $\mathrm{O}_{2}$ consumption $\left(\mathrm{ml} \cdot \mathrm{min}^{-1}\right)$ & $21.6 \pm 2.6$ & $20.6 \pm 3.9$ & $20.0 \pm 5.1$ & $20.4 \pm 7.2$ \\
\hline \multicolumn{5}{|l|}{ Placental glucose entry $\left(\mathrm{mg} \cdot \mathrm{min}^{-1}\right)\left(\mu \mathrm{mol} \cdot \mathrm{min}^{-1}\right)$} \\
\hline From uterine circulation & $\begin{array}{l}62.2 \pm 12.0 \\
(346 \pm 67)\end{array}$ & $\begin{array}{l}33.4 \pm 9.7 \\
(186 \pm 54)\end{array}$ & $\begin{array}{l}38.3 \pm 27.0 \\
(213 \pm 150)\end{array}$ & $\begin{array}{l}35.1 \pm 10.6 \\
(195 \pm 59)\end{array}$ \\
\hline From umbilical circulation & $\begin{array}{l}-22.3 \pm 2.7 \\
(-124 \pm 15)\end{array}$ & $\begin{array}{c}10.3 \pm 6.6^{*} \\
(57 \pm 37)\end{array}$ & $\begin{array}{l}9.2 \pm 2.8^{*} \\
(51 \pm 16)\end{array}$ & $\begin{array}{c}10.3 \pm 4.0^{*} \\
(57 \pm 22)\end{array}$ \\
\hline \multicolumn{5}{|l|}{ Net placental glucose entry $\left(\mathrm{mg} \cdot \mathrm{min}^{-1}\right)$} \\
\hline$\left(\mathrm{Q}_{\mathrm{plac}}\right)\left(\mu \mathrm{mol} \cdot \mathrm{min}^{-1}\right)$ & $\begin{array}{l}39.8 \pm 10.7 \\
(221 \pm 59)\end{array}$ & $\begin{array}{l}44.1 \pm 12.9 \\
(245 \pm 72)\end{array}$ & $\begin{array}{l}47.6 \pm 25.7 \\
(264 \pm 143)\end{array}$ & $\begin{array}{l}45.4 \pm 14.9 \\
(252 \pm 83)\end{array}$ \\
\hline$\%$ fetal contribution & 0 & $23 \% *$ & $19 \% *$ & $22 \% *$ \\
\hline \multicolumn{5}{|l|}{ Placental lactate production $\left(\mu \mathrm{mol} \cdot \mathrm{min}^{-1}\right)$} \\
\hline To uterine circulation & $-98 \pm 112$ & $87 \pm 66$ & $106 \pm 176$ & $95 \pm 102$ \\
\hline To umbilical circulation & $58 \pm 108$ & $395 \pm 86$ & $537 \pm 265$ & $455 \pm 116$ \\
\hline Net placental lactate production & $-39 \pm 150$ & $477 \pm 128$ & $644 \pm 468$ & $553 \pm 212 \dagger$ \\
\hline
\end{tabular}

\footnotetext{
$* p<0.01$.
}

$\dagger p<0.05$

Table 5. Relationship between insulin concentrations and substrate concentrations and entry rates: linear regression analyses

\begin{tabular}{|c|c|c|c|c|c|c|}
\hline $\mathrm{X}$ variable & Y variable & $n$ & Slope & Intercept & $r$ & $p$ \\
\hline \multicolumn{7}{|l|}{ Fetal } \\
\hline Glucose & Insulin & 83 & 0.39 & 2.24 & 0.43 & 0.001 \\
\hline Insulin & Fetal $Q_{L}$ & 19 & 3.45 & -9.33 & 0.53 & 0.02 \\
\hline Insulin & Fetal $Q_{\text {glu }}$ & 29 & 0.11 & 5.80 & 0.43 & 0.05 \\
\hline Log insulin & Fetal $Q_{\text {glu }}$ & 29 & 5.43 & 0.57 & 0.50 & 0.01 \\
\hline Insulin & Fetal $Q_{\text {glu }}+Q_{\mathrm{L}}$ & 17 & 3.66 & 54.70 & 0.47 & 0.02 \\
\hline Log insulin & Fetal $Q_{02}$ & 30 & 0.025 & 8.90 & 0.30 & 0.1 \\
\hline \multicolumn{7}{|l|}{ Maternal } \\
\hline Insulin & Uterine $\mathrm{Q}_{\mathrm{glu}}$ from basal & 18 & -0.61 & 40.9 & 0.59 & 0.01 \\
\hline
\end{tabular}

value of $-39 \pm 150 \mu \mathrm{mol} \cdot \mathrm{min}^{-1}$ (net placental lactate uptake) to $553 \pm 212 \mu \mathrm{mol} \cdot \mathrm{min}^{-1}$ (net placental lactate excretion) during the period of hyperglycemia (Table 4). As shown in Figure 4, this rise in net placental lactate production was related to the degree of fetal hyperglycemia produced. It should be noted that the mean value for control placental lactate production was negative (Fig. 4) because of a significant negative control uterine lactate excretion rate (net uterine lactate uptake from the maternal circulation) in one preparation (closed squares, Figs. 3 and 4). Calculated placental lactate production as a fraction of glucose uptake (ratio of lactate production to glucose entry in $\mu \mathrm{mol}$. $\min ^{-1} \times 2$ ) rose from control (net placental lactate uptake, $p<$
0.01 ) and in the pooled data represented greater than $100 \%$ of glucose available for lactate production (Table 4).

No changes in fetal alanine concentrations or uptakes were noted during fetal hyperglycemia. Fetal control alanine uptake was $5.18 \pm 2.03 \mu \mathrm{mol} \cdot \mathrm{kg}^{-1} \cdot \mathrm{min}^{-1}\left(19.03 \pm 7.31 \mu \mathrm{mol} \cdot \mathrm{min}^{-1}\right)$. Neither maternal alanine concentrations nor uterine uptakes from the maternal circulation were altered by fetal hyperglycemia. Uterine alanine uptake was $1.49 \pm 3.85 \mu \mathrm{mol} \cdot \mathrm{kg}^{-1} \cdot \mathrm{min}^{-1}$ $\left(8.36 \pm 12.48 \mu \mathrm{mol} \cdot \mathrm{min}^{-1}\right)$. The uterine and umbilical alanine uptake were not significantly different from each other.

Fetal plasma arterial insulin concentrations (Table 2) rose significantly during fetal glucose infusion and remained elevated 
throughout the experimental period. The elevations in insulin concentration, although variable, were linearly related to the degree of fetal hyperglycemia produced. As shown in Table 5, the elevations in plasma insulin were related to increases in umbilical entry rates of glucose or lactate as well as their sum. No relationship was noted between fetal insulin concentrations and fetal oxygen consumption during hyperglycemia. In addition, stepwise linear regression analysis of fetal insulin concentration and fetal glucose entry versus fetal oxygen consumption failed to note improved correlation over the relationship between glucose versus oxygen consumption entry alone.

Maternal arterial plasma insulin concentrations rose during fetal hyperglycemia (Table 3 ) despite unchanged arterial glucose concentrations. Decrements in uterine uptake of glucose from the maternal circulation, however, were directly related $(r=0.59$, $p<0.01$, Table 5) to the degree of elevation in maternal insulin concentrations.

\section{DISCUSSION}

Chronic fetal hyperglycemia is one of the numerous chemical abnormalities noted in assessment of the pregnant diabetic woman $(16,17)$. Although other abnormal metabolic findings, such as episodic elevations in maternal blood concentrations of amino acids, fats, and ketone bodies occur, (16-19) the development of significant maternal hyperglycemia appears to be a cardinal, and usually longstanding event. Although past work has been done in animals to assess the fetal metabolic alterations induced by experimental maternal diabetes $(20,21)$, little has been done to investigate the fetal responses to chronic elevations of glucose concentration in the absence of other maternal metabolic derangements. Using a chronically catheterized fetal sheep preparation, fetal glucose infusions have been shown to induce a state of relative arterial hypoxemia in the lamb without significant changes in either the maternal milieu or that of a simultaneously sampled but noninfused twin (6). Severe fetal hyperglycemia can result in fetal hypoxia with consequent metabolic acidosis and fetal demise (22).

Recently, it has been demonstrated that the observed glucoseinduced hypoxemia in fetal sheep is due to an acceleration in the rate of fetal oxygen consumption (5), an indicator of the fetal metabolic rate (23). Glucose infusion of such magnitude to treble the fetal blood glucose concentration induced a $30 \%$ increase in fetal $\mathrm{O}_{2}$ consumption, primarily due to an increased efficiency of oxygen extraction from umbilical venous blood. Mild but significant elevations in preplacental arterial $\mathrm{pCO}_{2}$ were noted, and were linearly related to the increase in fetal $\mathrm{O}_{2}$ consumption, suggesting an increase in carbon dioxide production due to the glucose-induced acceleration of the fetal metabolic rate (24). The current study documents the alterations in delivery of major fetal substrates during the period of experimental hyperglycemia.

In the present study, controlled fetal glucose infusion induced an increase in the calculated fetal glucose entry rate of approximately $40 \%$ by the 3 rd infusion day. In the fetal lamb as well as the human, a clear correlation exists between maternal and fetal blood glucose concentrations $(25,26)$. Net umbilical glucose uptake in the sheep has been shown to be related closely to this maternofetal glucose concentration gradient (26). Elevation of fetal plasma glucose concentration to $60 \mathrm{mg} / \mathrm{dl}$ in the current experiments would be similar to that found at maternal plasma glucose concentrations of $150-200 \mathrm{mg} / \mathrm{dl}(26)$. Studies in human adults have also documented a significant correlation between rate of glucose delivery and rate of glucose utilization $(27,28)$ and, thus, fetal hyperglycemia, whether due to fetal glucose infusion or maternal hyperglycemia might be expected to produce stimulation of the fetal glucose utilization rate.

Although net fetal glucose entry rates during control or experimental periods in the current work are different from the actual fetal rates of glucose utilization, Hay et al. (29) have shown with radio tracer techniques, that significant correlation is apparent between the two. Since actual glucose utilization occurs at a rate somewhat in excess of exogenous glucose entry in the fetal lamb, significant endogenous glucose production is suspected. In addition, although hyperglycemia inhibits endogenous hepatic glucose production in the adult (27), a relative insensitivity to suppression of glucose production by glucose infusion has been observed in the neonate (30). The above studies would suggest that observed glucose entry rates in the current fetal study mirror, but probably underestimate the actual fetal glucose utilization rate.

Under steady state conditions, the glucose/oxygen quotient may be used as an indicator of the quantity of substrate available to account for fuel used in oxidative metabolism (23). Although stimulation of fetal oxygen consumption occurred during fetal lamb glucose infusion, no change in the fetal $\mathrm{G} / \mathrm{O}_{2}$ was observed. Thus, even if all glucose taken up were accounted for as oxidative substrate, accelerated uptake of other substrates must also have occurred.

Lactate uptake and utilization by the fetal lamb are now welldocumented phenomena (23). Lactate utilization could account for up to $25 \%$ of the fetal consumption of oxygen in the resting state. Although the control umbilical lactate uptakes in the current work were similar to those measured by Sparks et al (31), the $\mathrm{L} / \mathrm{O}_{2}$ of 0.12 was somewhat lower than those measured by others $(23,31)$. The reasons for this discrepancy are unclear but may represent a smaller sample size or differences in assay technique.

Placentas of several mammalian species (31-35) have been shown to produce significant quantities of lactate under aerobic conditions. Several investigators have shown in fetal sheep studies that the ovine placenta excretes lactate into both fetal and maternal circulations under normoxemic steady state conditions, with the umbilical circulation receiving a relatively larger fraction of placentally derived lactate $(9,31,34)$. In the current study, during hyperglycemia conditions, placental lactate production increased with concomitant elevations in both maternal and fetal lactate entry rates despite no increase in either placental oxygen consumption or glucose entry. Although the apparent contribution of glucose to placental lactate production exceeded the calculated rate of placental glucose entry, it must be pointed out that a great deal of interanimal variability was present, making estimates of the ratio of production to uptake of lactate inexact. Since placental oxygen consumption was unaltered during hyperglycemia (5), the data may be interpreted to indicate that a portion of the net placental lactate production rate during hyperglycemia may have been derived from nonglucose (i.e. amino acid) substrates. However, no changes in either uterine or umbilical alanine uptakes were noted. Alternatively, fetal hyperglycemia may have caused a significant shift away from the use of glucose as a placental fuel in favor of other potential placental substrates (36).

Some precedent exists for the concept of substrate-induced stimulation of placental lactate production. Although hyperglycemia was not induced in the study by Sparks et al. (31), it is interesting to note that in spontaneously hypoglycemic pregnant sheep, both placental glucose consumption and lactate production were decreased from those in normoglycemic sheep. Although Holzman et al. (32) could find no relation between glucose uptake and lactate production among term human placentas, Villee (35) demonstrated that the absence of media glucose markedly decreased lactate production by the human placenta. In addition, recent evidence for transplacental facilitated diffusion for lactate now exists (37). Thus, it would appear that placentally derived lactate is a significant fuel in fetal life and that under normoxemic circumstances fetal hyperglycemia induces an acceleration of placental lactate production with consequent increased fetal uptake. Although individual organ uptakes of lactate have not been measured, in vitro work (38) noting stimulation of hepatocyte respiration with a variety of substrates, including lactate, suggests that the contribution of 
fetal liver to glucose-induced fetal metabolic stimulation may be significant. The combined $\mathrm{G} / \mathrm{O}_{2}$ and $\mathrm{L} / \mathrm{O}_{2}$ quotients exceeded 1.00 during ovine fetal hyperglycemia and indicates significant conversion of glucose and lactate to other substrates.

Experimental fetal hyperglycemia was associated with a decrease in the uterine glucose uptake, similar to the results of Simmons et al. (39). This occurred without significant alteration of the net placental glucose uptake. The placental entry rates for glucose from the fetus increased from a net fetal entry from placenta to $22 \%$ of the total placental glucose uptake (net fetal exit to placenta). Anand et al. (40) have documented bidirectional placental glucose transfer in sheep but it is unclear from the present study whether or not uterine glucose uptake decreased because of increased net fetomaternal glucose transfer, decreased placental utilization of maternal glucose, or both.

Fetal glucose infusion induced both fetal and maternal hyperinsulinemia. Significant evidence in adults is available to corroborate the view that excesses of substrate delivery can induce a state of temporary acceleration of the metabolic rate (41-44). The relative contributions of substrate versus insulin excess in the induction of metabolic stimulation, however, have been difficult to determine. Changes in maternal and fetal insulin concentrations were directly related to their respective glucose entry rates, but fetal insulin levels were consistently more variable than maternal levels. Significant relationships were apparent between the degree of fetal hyperinsulinemia and the elevation in fetal lactate entry rate, as well as glucose, but not between insulin concentration and fetal oxygen consumption.

Exogenous fetal insulin infusion has been shown to cause increases in glucose and oxygen uptake in fetal lambs $(45,46)$. It is possible that the contribution of endogenous insulin secretion to acceleration of substrate and oxygen uptake may have been obscurred due to variability in insulin concentrations previously noted $(5,6)$ or because of the relatively modest degree of fetal hyperinsulinemia produced. Alternatively, information from experiments in adult humans (27) suggests that rate of glucose infusion may be of greater importance than insulin concentration in determining tissue glucose uptake. Further work using $\beta$ cell suppression during hyperglycemia would be necessary to investigate this question further. Unlike the fetus or ewe, placental glucose uptake was not stimulated by fetal or maternal hyperinsulinemia, corroborating work in several mammalian species in vitro $(35,47)$. The data suggest, however, that a relatively larger percentage of the observed rate of placental glucose uptake could be accounted for by placental lactate production.

In summary, chronic fetal glucose infusion induced a state of accelerated fetal metabolism with a significant increase in the fetal glucose entry rate. Fetal hyperglycemia stimulated placental lactate production without increasing placental glucose uptake and induced enhancement of both fetal and maternal lactate uptakes. Fetal lactate may become an increasingly important oxidative substrate in the normoxemic but hyperglycemic fetal lamb.

Acknowledgments. The authors acknowledge the excellent secretarial assistance of Mary Ann Peifer.

\section{REFERENCES}

1. Cornblath M, Schwartz R 1976 Infant of the diabetic mother. In: Disorders of Carbohydrate Metabolism in Infancy. WB Saunders, Philadelphia, pp 115154

2. Francois R, Picand JJ, Ruitton-Ugliengo A, David L, Cartal MJ, Bauer D 1974 The newborn of diabetic mothers. Biol Neonate 24:1-31

3. Naeye RL 1965 Infants of diabetic mothers: a quantitative morphologic study. Pediatrics 35:980-988

4. VanAssche FA 1973 The fetal endocrine pancreas. In: Sutherland HW, Stowers JM (eds) Carbohydrate Metabolism in Pregnancy and the Newborn. Churchill Livingstone, Edinburgh, pp 68-82

5. Philipps AF, Porte PJ, Stabinsky S, Rosenkrantz TS, Raye JR 1984 Effects of chronic fetal hyperglycemia upon oxygen consumption in the ovine uterus and conceptus. $J$ Clin Invest 74:279-286

6. Philipps AF, Dubin JW, Matty PJ, Raye JR 1982 Arterial hypoxemia and hyperinsulinemia in the chronically hyperglycemia fetal lamb. Pediatr Res 16:653-658

7. Philipps AF, Carson BA, Meschia G, Battaglia FC 1978 Insulin secretion in fetal and newborn sheep. Am J Physiol 235:E467-E474

8. Meschia G, Cotter JR, Makowski EL, Barron DH 1967 Simultaneous measurement of uterine and umbilical blood flow and oxygen uptake. Q J Exp Physiol 52:1-8

9. Meschia G, Battaglia FC, Hay WH, Sparks JW 1980 Utilization of substrates by the ovine placenta in vivo. Fed Proc 39:245-249

10. Barnes RJ 1976 Water and mineral exchange between maternal and fetal fluids In: Beard RW, Nathanielsz PW (eds) Fetal Physiology and Medicine. WB Saunders, Philadelphia, pp 194-214

11. Koong LJ, Garrett WN, Rattray PV 1975 A description of the dynamics of fetal growth in sheep. J Anim Sci 41:1065-1068

12. Boyd RDH, Morriss FH Jr, Meschia G, Makowski EL, Battaglia FC 1973 Growth of glucose and oxygen uptakes by fetuses of fed and starved ewes. Am J Physiol 225:897-902

13. Schreiner RL, Burd LI, Jones MD Jr, Lemons JA, Sheldon RE, Simmons MA, Battaglia FC, Meschia G 1978 Fetal metabolism in fasting sheep. In: Longo L, Reneau D (eds) Circulation of the Fetus and Newborn. Garland Press, New York, pp 197-222

14. Olsen $C 1971$ An enzymatic fluorometric micro method for the determination of acetoacetate, hydroxybutyrate, pyruvate, and lactate. Clin Chim Acta 33:293-300

15. Bergmeyer NY 1974 Methods of Enzymatic Analysis. Academic Press, New York, pp 1679

16. Persson B, Lunell NO 1975 Metabolic control in diabetic pregnancy: variations in plasma concentrations of glucose, free fatty acids, glycerol, ketone bodies, insulin and human chorionic somatomammotropin during the last trimester. Am J Obstet Gynecol 22:737-745

17. Gillmer MDG, Beard RW, Brooke FM, Oakley NW 1975 Carbohydrate metabolism in pregnancy: diurnal plasma glucose profile in normal and diabetic women. Br Med J 3:399-404

18. Rigg L, Cousins L, Hollingsworth D, Brink G, Yen SSC 1980 Effects of exogenous insulin on excursions and diurnal rhythm of plasma glucose in pregnant diabetic patients with and without residual $\beta$-cell function. Am J Obstet Gynecol 136:537-544

19. Hollingsworth DR 1983 Endocrine and metabolic homeostasis in diabetic pregnancy. Clin Perinatol 10:593-614

20. Mintz DH, Chez RA, Hutchinson DL 1972 Subhuman primate pregnancy complicated by streptozotocin-induced diabetes mellitus. J Clin Invest 51:837-847

21. Pitkin RM, Plank CJ, Filer LJ Jr 1971 Fetal and placental composition in experimental maternal diabetes. Proc Soc Exp Biol Med 138:163-166

22. Robillard JE, Sessions C, Kennedy RL, Smith FG Jr 1978 Metabolic effects of constant hypertonic glucose infusion in well-oxygenated fetuses. Am J Obstet Gynecol 130:199-203

23. Battaglia FC, Meschia G 1978 Principle substrates of fetal metabolism. Physiol Rev 58:499-527

24. Hill EP, Power GG, Longo LD 1973 A mathematical model of carbon dioxide transfer in the placenta and its interaction with oxygen. Am J Physiol 224:283-299

25. Gabbe SG, Quilligan EJ 1977 Fetal carbohydrate metabolism: its clinical importance. Am J Obstet Gynecol 127:92-103

26. Simmons MA, Meschia G, Makowski EL, Battaglia FC 1974 Fetal metabolic response to maternal starvation. Pediatr Res 8:830-836

27. Wolfe RR, Allsop JR, Burke JF 1979 Glucose metabolism in man: responses to intravenous glucose infusion. Metabolism 28:210-220

28. Welle SL, Campbell RG 1983 Improved carbohydate tolerance and stimulation of carbohydrates oxidation and lipogenesis during short-term carbohydrate overfeeding. Metabolism 32:889-893

29. Hay WW, Sparks JW, Quissell BJ, Battaglia FC, Meschia G 1981 Simultaneous measurements of umbilical uptake, fetal utilization rate and fetal turnover rate of glucose. Am J Physiol 240:E662-E668

30. Cowett RM, Susa JB, Oh W, Schwartz R 1978 Endogenous glucose production during constant glucose infusion in the newborn lamb. Pediatr Res 12:853857

31. Sparks JW, Hay WW Jr, Bonds D, Meschia G, Battaglia FC 1982 Simultaneous measurements of lactate turnover rate and umbilical lactate uptake in the fetal lamb. J Clin Invest 70:179-192

32. Holzman IR, Philipps AF, Battaglia FC 1979 Glucose metabolism lactate, and ammonia production by the human placenta in vitro. Pediatr Res 13:117120

33. Block SM, Johnson RL, Sparks JW, Meschia G, Battaglia FC 1983 Uterine metabolism of the chronically catheterized pregnant guinea pig. Pediatr Res $17: 129 \mathrm{~A}$

34. Char VC, Creasy RK 1976 Lactate and pyruvate as fetal metabolic substrates. Pediatr Res 10:231-234

35. Villee CA 1953 The metabolism of human placenta in vitro. J Biol Chem 205:113-123

36. Olivera AA, Meigs RA 1975 Mitochondria from human term placenta. II Characterization of respiratory pathways and coupling mechanisms. Biochim Biophys Acta 376:436-445.

37. Moll W, Girard H, Gros G 1980 Facilitated diffusion of lactic acid in the guinea pig placenta. Pfluegers Arch Eur J Physiol 385:229-238 
38. Berry MN 1973 Energy demand of endogenous metabolism and gluconeogenesis in liver cells from normal and hyperthyroid rats. In: Lundquist $F$, Tygstrup N (eds) Regulation of Hepatic Metabolism. Munksgaard, Copenhagen, pp 568-578

39. Simmons MA, Battaglia FC, Meschia G 1979 Placental transfer of glucose. J Dev Physiol 1:227-243

40. Anand RS, Sperling MA, Ganguli S, Nathanielsz PW 1979 Bidirectional placental transfer of glucose and its turnover in fetal and maternal sheep. Pediatr Res 13:783-787

41. Garrow JS 1978 Factors affecting energy output. In: Energy Balance and Obesity in Man, 2nd ed. Elsevier-North Holland, Amsterdam, pp 95-98

42. Askanazi J, Rosenbaum SH, Hyman AI, Silverberg PA, Milic-Emili J, Kenney JM 1980 Respiratory changes induced by the large glucose loads of total parenteral nutrition. JAMA 243:1444-1447
43. Thiebaud D, Schutz Y, Acheson K, Jacot E, DeFronzo RA, Felber JP, Jaquier $\mathrm{E} 1983$ Energy cost of glucose storage in humans and subjects during glucoseinsulin infusions. Am J Physiol 244:E216-E221

44. Welle S, Lilavivat U, Campbell RG 1981 Thermic effect of feeding in man: increased plasma norepinephrine levels following glucose but not protein or fat consumption. Metabolism 10:953-958

45. Carson BS, Philipps AF, Simmons MA, Battaglia FC, Meschia G 1980 Effects of a sustained insulin infusion upon glucose uptake and oxygenation of the ovine fetus. Pediatr Res 14:147-152

46. Milley JR, Rosenberg AA, Philipps AF, Molteni RA, Jones MD Jr, Simmons MA 1984 The effect of insulin on ovine fetal oxygen extraction. Am J Obstet Gynecol 149:673-678

47. Szabo AJ, Grimaldi RD 1970 The effect of insulin on glucose metabolism of the incubated human placenta. Am J Obstet Gynecol 106:75-78

\title{
Long-Chain Acyl Coenzyme A Dehydrogenase Deficiency: An Inherited Cause of Nonketotic Hypoglycemia
}

\author{
DANIEL E. HALE, MARK L. BATSHAW, PAUL M. COATES, FRANK E. FRERMAN, \\ STEPHEN I. GOODMAN, INDERJIT SINGH, AND CHARLES A. STANLEY \\ The Children's Hospital of Philadelphia and the Department of Pediatrics, University of Pennsylvania School of \\ Medicine, Philadelphia, Pennsylvania 19104 [D.E.H., P.M.C., C.A.S.]; Department of Pediatrics and Neurology \\ and the John F. Kennedy Institute, Johns Hopkins Medical Institutions, Baltimore, Maryland 21205 [M.L.B., \\ I.S.]; Department of Microbiology, Medical College of Wisconsin, Milwaukee, Wisconsin 53226 [F.E.F.]; \\ Department of Pediatrics, University of Colorado School of Medicine, Denver, Colorado 80262 [S.I.G.]
}

\begin{abstract}
Three children from unrelated families presented in early childhood with hypoglycemia and cardiorespiratory arrests associated with fasting. Significant hepatomegaly, cardiomegaly, and hypotonia were present at the time of initial presentation. Ketones were not present in the urine at the time of hypoglycemia in any patient; however, dicarboxylic aciduria was documented in one patient at the time of the acute episode and in two patients during fasting studies. Total plasma carnitine concentration was low with an increased esterified carnitine fraction. These findings suggested a defect in mitochondrial fatty acid oxidation, and specific assays were performed for the acyl coenzyme $A(C o A)$ dehydrogenases. These analyses showed that the activity of the long-chain acyl CoA dehydrogenase was less than $10 \%$ of control values in fibroblasts, leukocytes, and liver tissue. Activities of the medium-chain, short-chain, and isovaleryl CoA dehydrogenases were not different from control values. With cultured fibroblasts, $\mathrm{CO}_{2}$ evolution from long-chain fatty acids was significantly reduced, while $\mathrm{CO}_{2}$ evolution from mediumchain and short-chain fatty acids was comparable to control values-findings consistent with a defect early in the $\beta$ -
\end{abstract}

Received November 21, 1984; accepted February 27, 1985.

Reprint requests Daniel E. Hale, M.D., Division of Endocrinology/Diabetes, The Children's Hospital of Philadelphia, 34th and Civic Center Boulevard, Philadelphia, PA 19104

Supported by NIH Grants PO1-NS 17752, 5-K01-AM 01226, HD 10981, 5 T32-AM07314, RR-00240, GM 25494, AM 15527, HD 16600, HD 08315, RR00052, and'a grant from the National Reye's Syndrome Foundation of Bryan, $\mathrm{OH}$. oxidation sequence. Studies of acyl CoA dehydrogenase activities in fibroblasts and leukocytes from parents of the patients showed levels of long-chain acyl CoA dehydrogenase activity intermediate between affected and control values and indicated an autosomal recessive form of inheritance of this enzymatic defect. These results describe a previously unrecognized metabolic disorder of fatty acid oxidation due to a deficiency of the long-chain acyl CoA dehydrogenase which may present in early childhood with disastrous consequences. This diagnosis should be considered in children who present with nonketotic hypoglycemia, carnitine insufficiency, and inadequately explained cardiorespiratory arrests. (Pediatr Res 19: 666-671, 1985)

\section{Abbreviations}

CoA, coenzyme A

ETF, electron transfer flavoprotein

A heterogeneous group of patients has been described with fasting intolerance presumed to result from defects in fatty acid metabolism (1-8). This conclusion has been drawn from a number of laboratory findings, including markedly elevated free fatty acids without consequent elevation of ketone bodies in the presence of hypoglycemia, and dicarboxylic aciduria. In some 